\title{
Albuminuria and Glomerular Damage in Mice Lacking the Metabotropic Glutamate Receptor 1
}

\author{
Aldamaria Puliti, ${ }^{\star \dagger}$ Pia Irene Anna Rossi, ${ }^{, \dagger}$ \\ Gianluca Caridi, ${ }^{\ddagger}$ Alessandro Corbelli, ${ }^{\S}$ \\ Masami Ikehata, ${ }^{\S}$ Silvia Armelloni, ${ }^{\S}$ Min Li, ${ }^{\S}$ \\ Cristina Zennaro, ${ }^{\ddagger}$ Valerio Conti, ${ }^{*}$ \\ Carlotta Maria Vaccari, ${ }^{+\dagger}$ Michela Cassanello, ${ }^{+\uparrow}$ \\ Maria Grazia Calevo," Laura Emionite, ** \\ Roberto Ravazzolo, ${ }^{* \dagger}$ and Maria Pia Rastaldi ${ }^{\S}$ \\ From the Molecular Genetics and Cytogenetics Unit, the \\ Laboratory on Pathophysiology of Uremia, ${ }^{*}$ the Laboratory for the \\ Study of Inborn Errors of Metabolism, " and the Scientific \\ Direction," G. Gaslini Institute, Genova; the Department of \\ Pediatrics and the Centre of Excellence for Biomedical Research, ${ }^{\dagger}$ \\ University of Genova, Genova; the Renal Research Laboratory, \\ Fondazione IRCCS Ospedale Maggiore Policlinico and \\ Fondazione D'Amico per la Ricerca sulle Malattie Renali, \\ Milano; and the Animal Facility,** National Cancer Institute, \\ Genova, Italy
}

The metabotropic glutamate (mGlu) receptor 1 (GRM1) has been shown to play an important role in neuronal cells by triggering, through calcium release from intracellular stores, various signaling pathways that finally modulate neuron excitability, synaptic plasticity, and mechanisms of feedback regulation of neurotransmitter release. Herein, we show that Grm1 is expressed in glomerular podocytes and that a glomerular phenotype is exhibited by Grm1 ${ }^{\text {crv } 4}$ mice carrying a spontaneous recessive inactivating mutation of the gene. Homozygous Grm1 $1^{\text {crva/crva }}$ and, to a lesser extent, heterozygous mice show albuminuria, podocyte foot process effacement, and reduced levels of nephrin and other proteins known to contribute to the maintenance of podocyte cell structure. Overall, the present data extend the role of mGlu1 receptor to the glomerular filtration barrier. The regulatory action of mGlu1 receptor in dendritic spine morphology and in the control of glutamate release is well acknowledged in neuronal cells. Analogously, we speculate that mGlu1 receptor may regulate foot process morphology and intercellular signaling in the podocyte. (Am J Pathol 2011, 178:1257-1269; DOI: 10.1016/j.ajpath.2010.11.050)
Increasing data provide evidence in favor of the hypothesis that glutamate intercellular signaling in the kidney, mostly driven by podocytes, is relevant to the health of the glomerular filter. Podocytes are highly differentiated cells with a complex ramified structure resembling that of neuronal cells. In common with neurons, podocytes use the same machinery for process formation in such highly arborized structures and possess the necessary vesicular and receptor apparatuses to use glutamatergic transmission. ${ }^{1,2}$ As recently proved, glutamatergic signaling is relevant to the maintenance of glomerular filter integrity because its dysregulation is accompanied by podocyte alterations and increased albuminuria. ${ }^{2}$

Glutamate is known to be the most abundant excitatory neurotransmitter in the central nervous system. Once released into the synaptic cleft from presynaptic terminals, glutamate can bind to glutamate receptors of two categories: the ionotropic glutamate receptors, which are ligand-gated ion channels that mediate fast excitatory neurotransmission, and the G protein-coupled metabotropic glutamate (mGlu) receptors, which mediate slower, modulatory neurotransmission (reviewed by Olive ${ }^{3}$ ). Three different types of ionotropic glutamate receptors are located on the postsynaptic dendritic spine: the $N$ methyl-D-aspartate (NMDA) receptor, the $\alpha$-amino-3-hydroxy-5-methylisoxazole-4-propionic acid (AMPA) receptor, and the kainate receptor. The NMDA and AMPA receptors are heterotetrameric protein complexes that regulate the influx of cations (primarily $\mathrm{Ca}^{2+}$ ions) into the neuronal cells. Kainate receptors are tetrameric protein complexes composed of various subunits permeable to $\mathrm{Na}^{+}$and $\mathrm{K}^{+}$ions, and, together with the NMDA and AMPA receptors, they contribute to excitatory postsynaptic currents.

Supported by RFPS-4-631972 grant "Genetic Bases of Birth Defects" from the Italian Ministry of Health; Progetto a Concorso 2008-2009 Fondazione IRCCS Policlinico; Renal Child Foundation; Fondazione D'Amico per la Ricerca sulle Malattie Renali; and Fondazione La Nuova Speranza.

Accepted for publication November 1, 2010.

Supplemental material for this article can be found at http://ajp. amjpathol.org or at doi: 10.1016/j.ajpath.2010.11.050.

Address reprint requests to Aldamaria Puliti, Ph.D., Laboratory of Molecular Genetics, G. Gaslini Institute, Largo G. Gaslini 5, 16148 Genova, Italy. E-mail: apuliti@unige.it. 
The mGlu receptors comprise a unique family of at least eight $G$ protein-coupled subtypes (mGlu1 to mGlu8) subdivided into three groups (I, II, and III) and differentiated on the basis of sequence similarity, $G$ protein-coupling specificity, and pharmacologic profile. $^{4}$

In neurons, the mGlu1 receptor (gene symbol GRM1) has been shown to be expressed at postsynaptic and presynaptic membranes. By releasing calcium from intracellular stores, it triggers various signaling pathways that finally modulate neuron excitability, synaptic plasticity, mechanisms of neuroprotection, and feedback regulation of neurotransmitter release..$^{5-12}$ In particular, the mGlu1 receptor has been shown to play an important role in neuronal cells by regulating the shape of dendritic spines. ${ }^{13}$ At the presynaptic level, it regulates glutamate release. ${ }^{12}$ The NMDA receptor subunits have also been found to exist on presynaptic terminals, ${ }^{14}$ and functional interactions between mGlu1 and NMDA receptors have recently been demonstrated at least at noradrenergic presynaptic terminals, where mGlu1 receptors contribute to the evoked noradrenaline release by enhancing NMDA receptor activity. ${ }^{15}$

Although most research in the mGlu receptors field has been "synaptically oriented," recent data extend the role of these receptors to other biological processes. Molecular analyses show functional expression of mGlu receptors in several nonneuronal cells, including bone, ${ }^{16}$ testis, ${ }^{17}$ and T cells, ${ }^{18,19}$ indicating possible glutamate signaling in different systems (reviewed by Nicoletti and colleagues ${ }^{20}$ ). At present, however, no data have been reported, to our knowledge, on a possible role in the kidney.

We have been investigating a mouse carrying the spontaneous recessive mutation cervelet-4 (crv4) in the Grm1 gene that causes lack of mGlu1 receptor function and a complex phenotype mainly characterized by ataxia and intention tremor due to impaired cerebellar activities. ${ }^{21}$ To verify whether mGlu1 receptor could possibly be involved in glomerular function, we first studied its potential expression in the kidney. Then, taking advantage of the availability of Grm1 ${ }^{\text {crv }} 4$ mice, we analyzed in vivo the renal effects of the lack of functional mGlu1 receptor.

\section{Materials and Methods}

\section{Animals}

The crv4 mutation is a spontaneous recessive mutation that occurs in the $B A L B / \mathrm{c} /$ Pas inbred strain. ${ }^{21}$ It consists of a long terminal repeat intronic insertion that disrupts splicing of the mG/uR1 gene and causes absence of the protein. Affected Grm1 $1^{\mathrm{crv} 4 / \mathrm{crv} 4}$ and control Grm $1^{+/+}$mice are maintained on the same genetic background by intercrossing heterozygous Grm1 $1^{+/ c r v 4}$ mice at the Animal Facility of the National Cancer Institute in Genova. All the experimental procedures were performed according to the national current regulations regarding the protection of animals used for scientific purposes (D.L.vo 27/01/ 1992, n. 116) and were reviewed and approved by the ethical committee for animal experimentation (Comitato per la sperimentazione etica sugli animali). The genotype of the wild-type and Grm1 $1^{\text {crv }}$ mice was determined by means of PCR using tail genomic DNA and specific primers as previously reported. ${ }^{12}$

\section{RT-PCR and Human CDNA Library Screening}

The human cDNA library (MTC Multiple Tissue cDNA Panels I and II, Clontech Laboratories, Mountain View, CA), 1 $\mu \mathrm{L}$ of cDNA for each tissue sample, was screened by using the GRM1-specific primers Hgrm1F (5'-TGCTGCTGGATTTGCACGGC-3') and Hgrm1R (5'-TTGCTGCCAGCCAGGATGCG-3'), with 35 PCR amplification cycles. Amplified products obtained from cerebellum and kidney were purified from the agarose gel and were sequenced on both strands using BigDye dideoxy terminator chemistry on an ABI 3100 DNA sequencer (Applied Biosystems, Foster City, $\mathrm{CA})$.

Total RNA was extracted from cerebella, renal cortex, sieving-isolated renal glomeruli, and primary cultures of podocytes of wild-type and Grm1 $1^{\text {orv } 4 / c r v 4}$ mice and from an immortalized mouse podocyte cell line and was used to synthesize the first-strand cDNA with gene-specific primers, MGLUR1-R12 (5'-CCTCTCCAGACACTCCAACA-3') for mouse Grm1 gene, or oligo-dT primers, and the SuperScript III First-Strand Synthesis System for RT-PCR (Invitrogen, S. Giuliano Milanese, Italy). cDNA amplification was performed using GRM1-specific primers or primers specific for control (nephrin, podocin, and Gapdh) genes: MGLUR1-F3 (5'TACCCCCAGGCAGGACTAAG-3') and MGLUR1-R11 (5'GCATGGTGCATGTTCTGTAGG-3'); MGLUR1-F20 (5'-TCATACGGAAAGGGGAAGTG-3') and MGLUR1-R24 (5'CAGCACAAAGATGAGGGTGA-3'); MNephrin-F (5'AAGCTGGACGTGCATTATGCT-3') and MNephrin-R (5'CGGTGCAGACTATATCCACAGAAC-3'); Gapdh-F3 (5'ATTGTCAGCAATGCATCCTG-3') and Gapdh-R3 (5'ATGGACTGTGGTCATGAGCC-3'); and Mpodocin-F1 (5'TGAAGCGCCTCTTGGCACATCG-3') and Mpodocin-R2 (5'-TGCAAGTATCGAAGCTGGACAGCG-3'). PCR-specific bands were isolated from the agarose gel and were sequenced.

\section{Western Blot Analysis}

Western blots of cerebella, renal cortex, and sievingisolated glomeruli were performed according to established protocols ${ }^{21}$ with some modifications. In brief, cerebella and renal cortex were homogenized in buffer A (5 $\mathrm{mmol} / \mathrm{L}$ Tris, $\mathrm{pH}$ 7.2, $2 \mathrm{mmol} / \mathrm{L}$ EDTA, $10 \mathrm{mmol} / \mathrm{L}$ iodoacetamide, and protease inhibitors) and then were centrifuged at $30,000 \times g$ for 30 minutes at $4^{\circ} \mathrm{C}$ to collect a crude membrane pellet. The pellet was lysed in buffer $\mathrm{B}$ [20 mmol/L Tris- $\mathrm{HCl}, \mathrm{pH}$ 6.8, $150 \mathrm{mmol} / \mathrm{L} \mathrm{NaCl}, 10$ $\mathrm{mmol} / \mathrm{L}$ EDTA, $1 \mathrm{mmol} / \mathrm{L}$ EGTA, $1 \%$ Triton X-100, 10 $\mathrm{mmol} / \mathrm{L}$ iodoacetamide, and a protease inhibitor mixture (Roche Diagnostics $\mathrm{GmbH}$, Mannheim, Germany)] by quick sonication in short bursts while on ice. Isolated glomeruli were homogenized in lysis buffer $(10 \mathrm{mmol} / \mathrm{L}$ Tris- $\mathrm{HCl}, \mathrm{pH} 7.5,10 \mathrm{mmol} / \mathrm{L}$ EDTA, $0.5 \%$ Nonidet P-40, $0.1 \%$ SDS, $0.5 \%$ sodium deoxycholate, and protease inhibitors) by quick sonication in short bursts while on ice. Protein concentration was determined using the Bradford 
method (Bio-Rad, Hercules, CA), and samples were separated on $10 \%$ gel by means of SDS-polyacrylamide gel electrophoresis. Electroblotted proteins were monitored using Ponceau Red S staining. Membranes were then incubated with the following antibodies: anti-Grm1 monoclonal antibody (1:2500; BD Biosciences, San Jose, CA); guinea pig polyclonal anti-nephrin (GP-N2) (1:1000; PROGEN Biotechnik GmbH, Heidelberg, Germany); rabbit polyclonal anti-podocin (1:2000; Sigma-Aldrich Co., St. Louis, MO); mouse monoclonal anti-synaptopodin (1: 500; PROGEN); rabbit polyclonal anti- $\alpha$-actinin-4 (1: 5000; ImmunoGlobe, Himmelstadt, Germany); mouse monoclonal anti-ZO-1 (1:500; Invitrogen); rabbit polyclonal anti-CD2AP (1:1000; Abcam, Cambridge, England); and mouse monoclonal anti-Gapdh (1:10,000; Chemicon, Temecula, CA). After incubation with peroxidase-coupled secondary antibodies, protein bands were detected by using a Western blotting detection system (ECL; Amersham Biosciences, Piscataway, NJ). Bands were detected and analyzed for density using an enhanced chemiluminescence system (Versa-Doc 4000; Bio-Rad), and QuantityOne software (Bio-Rad).

For glycosidase treatment, each lysate sample $(20 \mu \mathrm{g})$ was treated with $1000 \mathrm{U}$ of pNGaseF (New England Biolabs, Ipswich, MA). The reactions were incubated at $37^{\circ} \mathrm{C}$ for 2 hours, and the samples were analyzed by means of Western blot as reported in the previous paragraph.

\section{Podocyte Cell Cultures}

For primary cultures, kidneys were taken from 7- to 10-

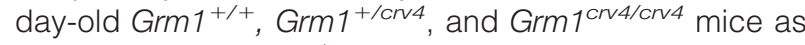
described previously. ${ }^{1}$ Briefly, glomeruli were isolated by sieving and then were seeded in culture flasks (Corning; Sigma-Aldrich, Milan, Italy) precoated with collagen type IV (Sigma-Aldrich) at $37^{\circ} \mathrm{C}$ in $5 \% \mathrm{CO}_{2}$ atmosphere. After 1 week, first-passage podocytes were separated from glomeruli by an additional sieving through $36-\mu \mathrm{m}$ mesh. Second-passage podocytes were seeded on flasks to be used for molecular analyses. Some of the cells were instead seeded on Thermanox coverslips (Nunc, VWR International, Milan, Italy) for immunofluorescence studies. Cell characterization was performed using morphologic assessment, immunofluorescence, and Western blot analysis (see Supplemental Figure S1 at $h$ ttp://ajp. amjpathol.org) using podocyte (nephrin and podocin), epithelial (cytokeratins), smooth muscle ( $\alpha$-SMA), and endothelial (CD31) cell markers.

The conditionally immortalized mouse podocyte cell line was obtained from transgenic $H-2 K^{b}$-tsA58 mice, as previously described. ${ }^{2}$ Cells were first propagated at $33^{\circ} \mathrm{C}$ in medium containing $20 \mathrm{U} / \mathrm{ml}$ of recombinant mouse interferon- $\gamma$ (Sigma-Aldrich) and then were thermo-shifted to $37^{\circ} \mathrm{C}$ and maintained in medium without interferon- $\gamma$ for 15 days. Differentiated cells were used in the experiments.

\section{Grm1 Silencing}

To down-regulate the mGlu1 receptor, differentiated podocytes were incubated in antibiotic-free medium
A

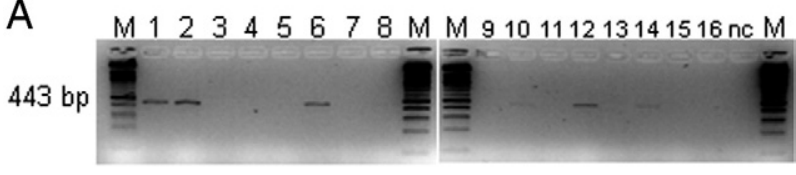

B Renal cortex

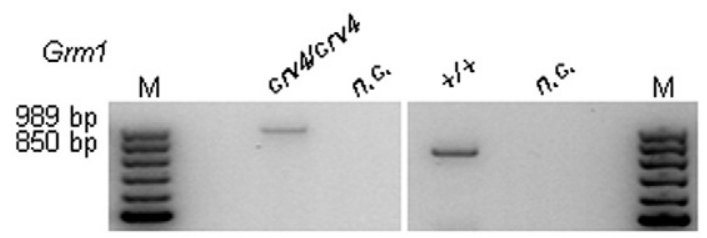

C

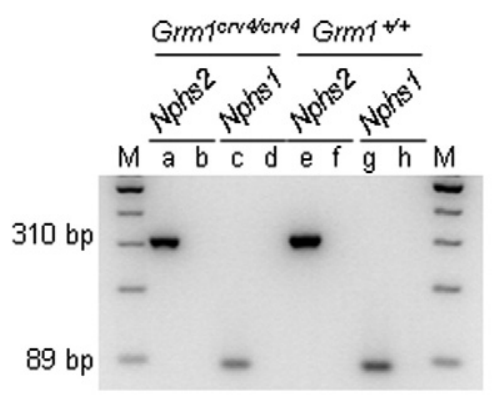

D

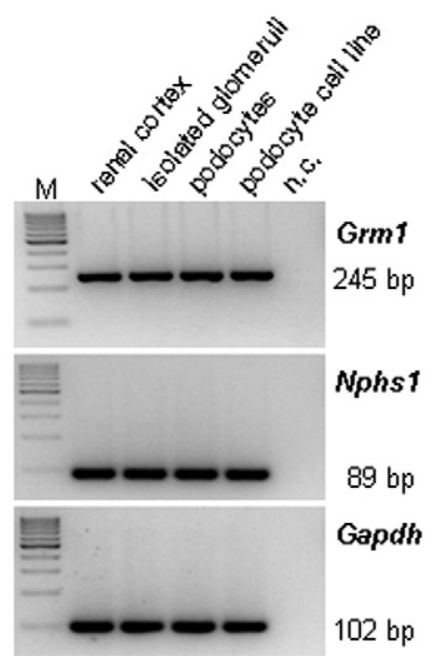

Figure 1. Evaluation of mGlu1 receptor expression by means of RT-PCR A: Screening of the human cDNA library (MTC Multiple Tissue cDNA panels I and II). Lane 1, heart; lane 2, brain; lane 3, placenta; lane 4, lung; lane 5, pancreas; lane 6, kidney; lane 7 , skeletal muscle; lane 8 , liver; lane 9 , spleen; lane 10 , thymus; lane 11, prostate; lane 12, testis; lane 13, peripheral blood leukocytes; lane 14, colon; lane 15, small intestine; and lane 16, ovary. nc, negative control; and M, 100-bp DNA ladder. B: Expression of mGlu1 receptor in the renal cortex of Grm $1^{\text {crvi/crut }}$ and wild-type mice by means of RT-PCR. n.c., negative control; M, 100-bp DNA ladder. The upper band represents the mutated sequence, and the lower band represents the wildtype sequence. Primers (MGLUR1-F3/MGLUR1-R11) have been drawn to amplify a fragment of the Grm1 encompassing the crv4 mutation and corresponding to a cDNA insertion of $139 \mathrm{bp}$. C: The quality of RNA extracted from renal cortex was evaluated by means of RT-PCR using primers specific for podocin (Nphs2) and nephrin (Nphs1) for mutated and wild-type mice. M, 100-bp DNA ladder. D: Expression of mGlu1 receptor in renal cortex, isolated renal glomeruli, primary podocytes from wild-type mice, and conditionally immortalized podocytes obtained by means of RT-PCR using primers (MGLUR1-F20/MGLUR1-R24). n.c., negative control; M, 100-bp DNA ladder. The quality of extracted RNA was evaluated by means of RT-PCR using primers specific for nephrin (Nphs1) and Gapdh. 
A

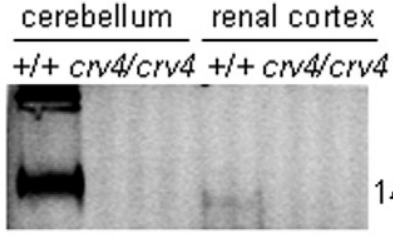

$140 \mathrm{kDa}$

Gapdh

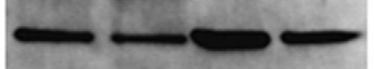

$38 \mathrm{kDa}$

B

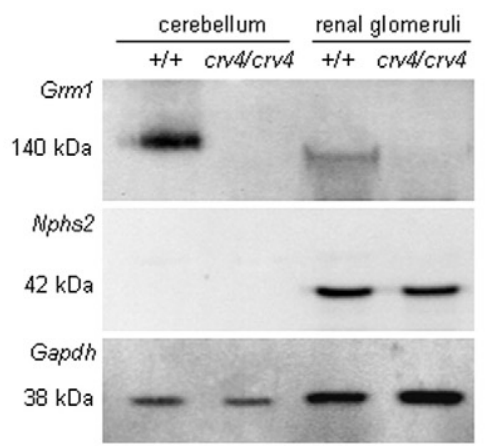

C

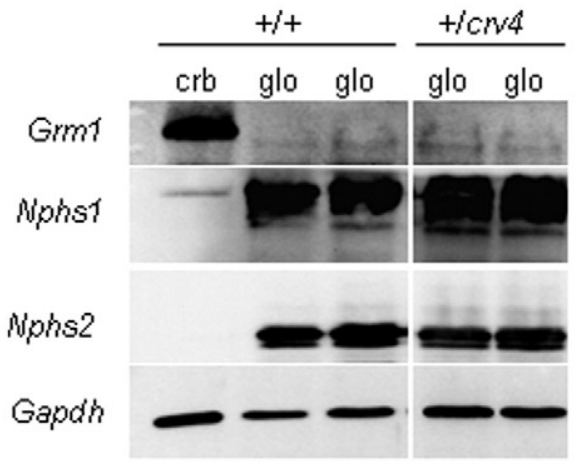

D Grm1 expression

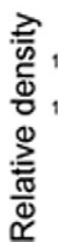

$\left.\begin{array}{l}50 \\ \infty \\ 50 \\ 0\end{array}\right]$
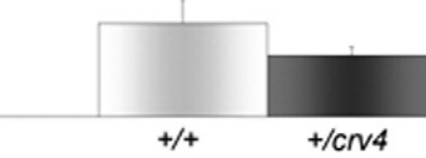

Figure 2. Western blot analysis of mGlu1 receptor in renal cortex (A) and isolated glomeruli (B) of wild-type and Grm $1^{\text {crv } 4 / c r v 4}$ mice. Thirty micrograms of proteins from renal cortex and $10 \mu \mathrm{g}$ of proteins from cerebellum per lane were applied to the SDS-polyacrylamide gel electrophoresis gel. Gapdh was used as a loading control, and nephrin (Nphs1) or podocin (Nphs2) was used as loading control for specific renal proteins. C: Representative Western blot analysis of mGlu1 receptor expression in isolated renal glomeruli obtained from wild-type (left) and heterozygous $G r m 1^{+/ c r v}$ (right) mice. Approximately $20 \mu \mathrm{g}$ of proteins from wild-type cerebellum (crb) and wild-type renal glomeruli (glo) per lane were applied to the SDS-polyacrylamide gel electrophoresis gel (left). In heterozygous Grm $1^{+/ \text {cru } 4}$ renal glomeruli, the presence of the mGlu1 receptor band is more evident by using double quantities of proteins as used for mGlu1 receptor detection in wild-type glomeruli (right). D: Quantification of mGlu1 receptor protein expression level. Data represent the mean $\pm S E$ percentage of $\mathrm{Grm} 1^{+/ \mathrm{crv} 4}$ versus wild-type mice of three mice for each group analyzed in duplicate by means of Western blotting. Expression levels are normalized for Gapdh in the same blotted membrane.
(Opti-MEM; Gibco, Invitrogen, Life Technologies, Carlsbad, CA) for 24 hours and then were transfected with 10and 20-nM small-interfering RNA (siRNA) duplexes, using Lipofectamine 2000 (Invitrogen, Life Technologies) as the transfection agent. We used a pool of two commercially available siRNAs complementary to Grm1 (Mm01_00091312 and Mm01_00091313; Sigma-Aldrich Co.). As a control, nontargeting siRNAs (Sigma-Aldrich Co.) were applied at the same concentrations. After 24 hours of incubation at $37^{\circ} \mathrm{C}$, the medium was replaced with a fresh one containing antibiotics. Transfection efficiency was determined using an siRNA tagged with a fluorescent dye (Alexa Fluor 488; Amersham, PerkinElmer, Waltham, MA), which resulted in higher than $70 \%$ efficiency, as estimated from the fluorescence distribution. Silencing of Grm1 and its cellular effects were evaluated 72 hours after siRNA transfection using parallel immunofluorescence and Western blot analyses.

\section{Renal Tissue Histologic Analysis}

Kidneys were taken from 2-, 4-, and 8-month-old animals (3 to $5 \mathrm{Grm} 1^{+/+}$, Grm1 ${ }^{+/ c r v 4}$, and $\mathrm{Grm} 1^{\mathrm{cr} 4 / \mathrm{crv} 4}$ mice, for a total of 30 animals) and were processed for routine light microscopy, transmission electron microscopy, and immunofluorescence studies according to established protocols. ${ }^{22}$

\section{Immunofluorescence Analysis}

An indirect immunofluorescence method was applied on 5 - $\mu \mathrm{m}$-thick acetone-fixed tissue cryosections and podocyte coverslips. Paraformaldehyde fixation was instead used before revealing F-actin by means of rhodaminelabeled phalloidin (Sigma-Aldrich).

The following primary antibodies were used for the study: rabbit anti-Grm1 (Santa Cruz Biotechnology, Santa Cruz, CA), rabbit anti-Grm1 antibody (Novus Biologicals, Littleton, CO), rabbit anti-mouse nephrin (intracellular domain) (\#035, provided by Harry Holthofer, University of Dublin, Ireland), guinea pig polyclonal anti-nephrin (GPN2) (PROGEN), mouse anti-synaptopodin (PROGEN), rabbit anti-podocin (Sigma-Aldrich Co.), rabbit anti-ZO-1 (Invitrogen), and rabbit anti-mouse serum albumin (Abcam). As secondary fluorescent-labeled antibodies, we used the following: Alexa Fluor 488 and Alexa Fluor 546 goat anti-rabbit IgG, Alexa Fluor 488 and Alexa Fluor 546 goat anti-mouse IgG highly cross adsorbed, and Alexa Fluor 488 goat anti-guinea pig IgG (Invitrogen).

For double stainings, sections/coverslips were first incubated with the first primary antibody followed by the appropriate secondary antibody. After adequate washing, the procedure was repeated for the second primary antibody. Specificity of antibody labeling was demonstrated by the lack of staining after substituting proper control Igs (rabbit primary antibody isotype control and mouse primary antibody isotype control, Invitrogen; and guinea pig primary antibody isotype control, Rockland Immunochemicals, Gilbertsville, PA) for the primary antibodies. Slides were mounted with FluorSave Reagent (Calbiochem, VWR International, Milano, Italy). 
Images were acquired using a Zeiss Axioscope 40FL microscope equipped with an AxioCam MRc5 digital video camera and immunofluorescence apparatus (Carl Zeiss SpA, Arese, Italy) and were recorded using AxioVision software 4.3. Further images were taken using a confocal laser scanning microscope (Radiance Plus; Bio-Rad, Hemel Hemstead, England) installed on a fluorescence microscope (Eclipse E600; Nikon, Tokyo, Japan). Digital images resulting from the confocal scanning microscopy were optimized for image resolution.

Quantitative evaluation was performed on digital images by running appropriate macros, essentially composed using color threshold procedures and filtering, applied on 30 consecutive glomerular areas per specimen selected as the region of interest. The software (AxioVision 4.7 Quantification Modules; Carl Zeiss MicroImaging $\mathrm{GmbH}$, Jena, Germany) was programmed to automatically calculate the percentage of the region of interest occupied by staining, and the results were exported to a spreadsheet file (Microsoft Excel; Microsoft Corp., Redmond, Washington).

\section{Immunogold Electron Microscopy}

An indirect immunogold labeling procedure was performed on ultrathin frozen kidney sections, as described previously. ${ }^{22}$ Briefly, after blocking, the material was incubated with the primary rabbit anti-Grm1 antibody followed by the secondary gold-conjugated goat anti-rabbit IgG $12 \mathrm{~nm}$ (Jackson ImmunoResearch Europe, Suffolk, England). Specificity of antibody labeling was demonstrated by the lack of staining after substituting a proper control Ig (Invitrogen) for the primary antibody.

\section{Urine Analyses}

Three replica spot urine samples per mouse were collected from 3- to 7-month-old Grm1 $1^{\text {crv4/crv4 }}$ ( $\left.n=20\right), \mathrm{Grm} 1^{+/ \mathrm{crv} 4}$ ( $n=16)$, and sex- and age-matched Grm1 ${ }^{+/+}(n=19)$ mice and centrifuged, and supernatant was conserved at $-80^{\circ} \mathrm{C}$. Urine albumin levels were measured in duplicate using the indirect competitive enzyme-linked immunosorbent assay Albuwell M kit (Exocell Inc., Philadelphia, PA). Urine creatinine levels were measured in the same
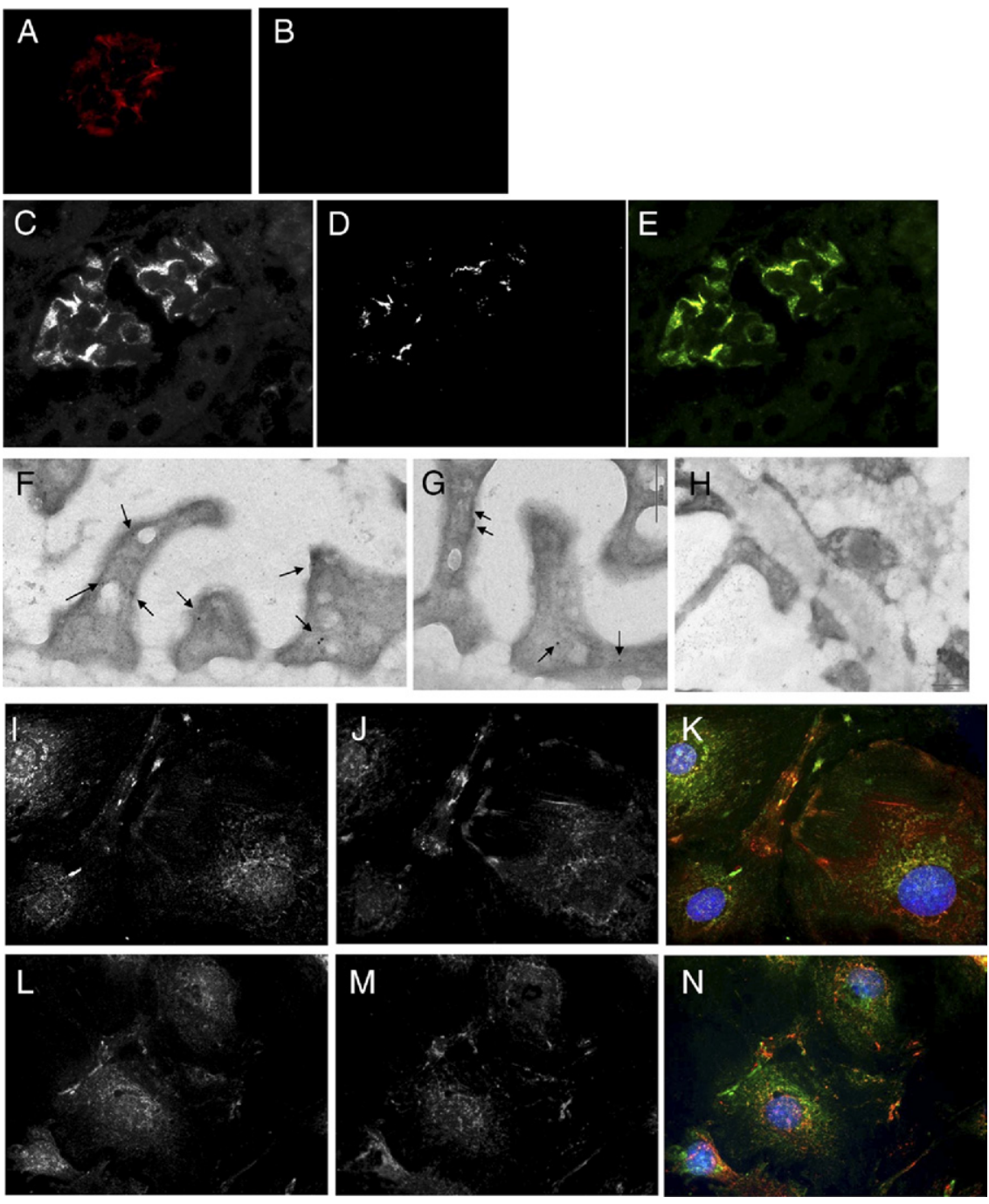

Figure 3. Immunofluorescence shows expression of the mGlu1 receptor in the glomerulus of a wild-type animal (A) and its complete absence from the renal tissue of a Grm1 $1^{\text {crva/crva }}$ mouse (B). Original magnification, $\times 400$. Immunofluorescence double staining of renal tissue conducted on $1-\mu \mathrm{m}$ semithin sections reveals glomerular co-staining of nephrin (C) and Grm1 (D) (merged in E) and confirms the comma-like pattern of Grm1 staining along the glomerular tuft. Original magnification, $\times 1000$. Gold particles can be observed in podocytes of wild-type tissues (arrows) (F and $\mathbf{G}$ ), whereas they are completely absent from glomeruli of Grm1 $1^{\text {crut }}$ crú animals $(\mathbf{H})$. Scale bar $=200 \mathrm{~nm}$. Immunofluorescence double staining (DAPI counterstain) of cultured podocytes shows co-localization of nephrin (I and $\mathbf{L}$ ) and Grm 1 ( $\mathbf{J}$ and $\mathbf{M}$ ) in small dots along cell processes (merged in $\mathbf{K}$ and $\mathbf{N}$ ). Original magnification, $\times 1000$. 
the control glomeruli was assumed to be equal to 1 . The $\mathrm{P}_{\text {alb }}$ was defined as $\left(1-\sigma_{\mathrm{alb}}\right)$ and described the movement of albumin subsequent to water flux. When $\sigma_{\text {alb }}$ is 0 , albumin moves across the membrane with the same velocity as water, and $\mathrm{P}_{\text {alb }}$ is 1.0; conversely, when $\sigma_{\text {alb }}$ is 1.0, albumin cannot cross the membrane with water, and $P_{\text {alb }}$ is 0 .

\section{Mean Foot Process Width Assessment Using Electron Microscopy}

Podocyte foot process effacement was evaluated according to established protocols. ${ }^{24}$ To measure mean foot process width (FPW), digital electron micrographs were acquired using a SIS Megaview II camera (Olympus
Soft Imaging Solutions GmbH, Munster, Germany) (original magnification, $\times 7900)$, and the system was calibrated using the scale bar on the electron micrographs. Six random capillary loops in each of five randomly selected glomeruli per specimen were selected, and the total circumference of the capillary loop was included in the image in $50 \%$ of cases. Foot processes were defined as any connected epithelial segment butting on the glomerular basement membrane and separated from the cytoplasmic extensions of the adjacent foot processes by lateral membrane. Only foot processes with lateral membranes clearly identifiable over the entire length were included. The FPW was determined by manually counting the number of foot processes overlying the peripheral
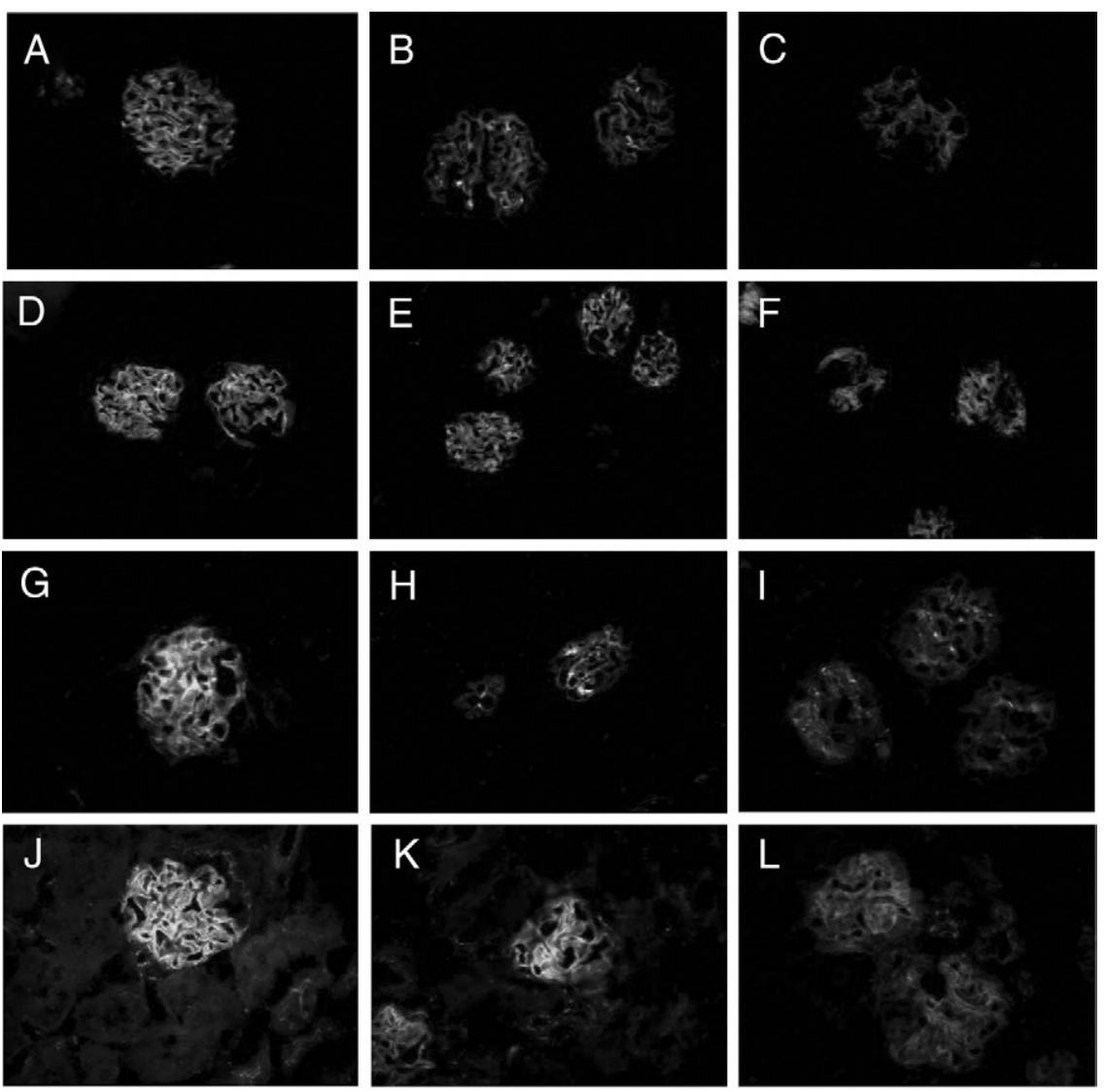

M

$\mathrm{N}$
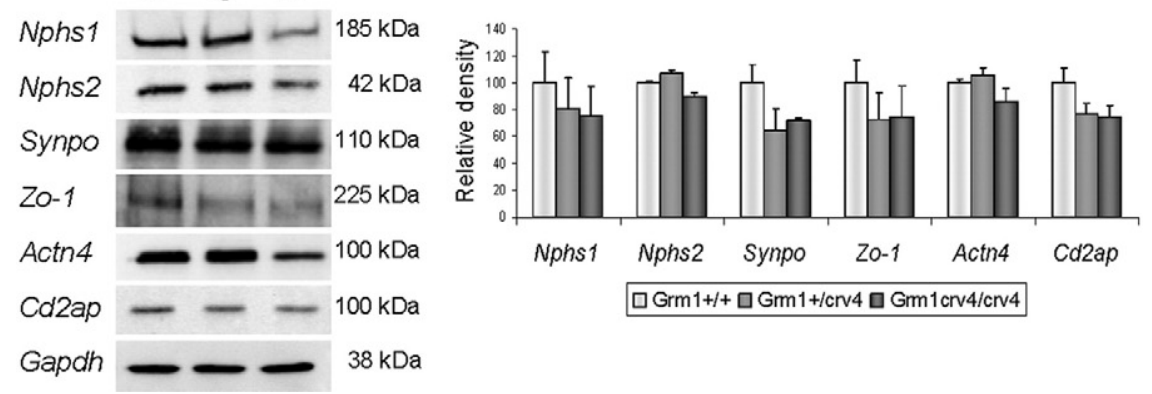

Figure 5. Podocyte proteins in 8-month-old animals. Immunofluorescence displays diffuse progressive loss of the podocyte markers nephrin (B and $\mathbf{C})$ and synaptopodin ( $\mathbf{E}$ and $\mathbf{F})$ and segmental loss of podocin ( $\mathbf{H}$ and $\mathbf{I})$ and ZO-1 (K and $\mathbf{L})$ in glomeruli of 8 month-old Grm1 $1^{+/ \text {crv } 4}$ and Grm $1^{\text {cru } 4 / c r u 4}$ mice, whereas wild-type glomeruli still have normal expression of all molecules (A, D, G, and $\mathbf{J}$ ). Original magnification: $\times 200$; $\times 400$. $\mathbf{M}$ and $\mathbf{N}$ : Western blot analysis of lysates from isolated glomeruli of 8-month-old wild-

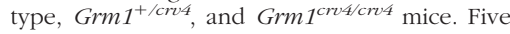
mice for each group were analyzed by means of Western blotting (20 $\mu \mathrm{g}$ of protein per lane) using specific antibodies as indicated. Expression levels are normalized for Gapdb in the same blotted membrane. M: Representative immunoreactive bands. Nphs1, nephrin; Nphs2, podocin; Synpo, synaptopodin; ZO-1, tight junction protein 1; Actn $4, \alpha$-actinin- 4 ; Cd2ap, cd2-associated protein; and Gapdh, glyceraldehyde-3phosphate dehydrogenase. N: Quantification of protein expression level. Data represent the mean \pm SE percentage of $\mathrm{Grm}^{+/ c r v 4}$ and Grm1 $1^{\text {cru4/crva }}$ versus wild-type mice. Original magnification $\times 200(\mathbf{D}, \mathbf{E}, \mathbf{F}) ; \times 400(\mathbf{A}-\mathbf{C}, \mathbf{G}-\mathbf{L})$. 
capillary basement membrane and measuring basement membrane length using image analysis software. The FPW was calculated as FPW $=(\pi / 4)^{\star} \Sigma \mathrm{BML} / \Sigma \mathrm{fp}$, where $\Sigma \mathrm{fp}$ is the number of foot processes counted on the 30 electron micrographs from each animal, $\Sigma$ BML is the total peripheral capillary basement membrane length for that animal, and $\pi / 4$ is a factor used to correct for presumed random variation in the angle of the section relative to the long axis of the foot process. Filtration slit width values were not subtracted; therefore, the reported FPW values represent, on average, the width of one foot process and the adjacent filtration slit.

\section{Adriamycin Nephropathy}

To examine whether the crv4 mutation could be responsible for increased susceptibility of podocytes to toxic/ environmental factors, six animals (three $\mathrm{Grm} 1^{+/+}$and three $\mathrm{Grm} 1^{\text {crv } 4 / \mathrm{crv} 4}$ ) at the age of 8 months were injected intravenously with adriamycin, $8 \mathrm{mg} / \mathrm{kg}$ body weight. Another six age- and sex-matched mice (three $\mathrm{Grm} 1^{+/+}$ and three Grm $1^{\text {crv } 4 / c r v 4}$ ) served as controls and were given vehicle alone $(0.9 \% \mathrm{NaCl})$. The dosage of adriamycin was lower than that in previously reported experiments (10 to $20 \mathrm{mg} / \mathrm{kg}$ body weight) to better appreciate possible differences between the strains. ${ }^{25}$

\section{Statistical Analysis}

The UAE data were described as mean \pm SE and median (range) for continuous variables, and absolute and relative frequencies were used for categorical variables. Normality of distribution was determined using QQ plots and the Kolmogorov-Smirnov test. Analysis of variance was used for continuous, normally distributed variables; a post hoc Bonferroni test was used to determine significance between multiple groups. Comparisons between subgroups were performed using the Kruskal-Wallis test or the U-test, as appropriate. A $P<0.05$ was considered significant, and all $P$ values were based on 2-tailed tests. Statistical analysis was performed using SPSS for Windows (SPSS Inc., Chicago, IL). In the $P_{\text {alb }}$ test, comparisons of means were performed using the $t$-test for unpaired data (2-tailed, $P<$ 0.05). Data from quantitative evaluation of digital images were analyzed using the $\chi^{2}$ test.

\section{Results}

Grm1 Is Expressed in Wild-Type Grm1 ${ }^{+/+}$ Kidney Glomeruli and Is Absent from Glomeruli and Podocytes of Grm1 ${ }^{\text {crv4/crv4 }}$ Mice

A systematic analysis of mRNA expression of the GRM1 gene in a human cDNA library by means of RT-PCR revealed GRM1 expressed, at different levels, in the brain and a few other tissues, including the kidney (Figure 1A).

We next investigated Grm1 expression in mouse renal tissues from wild-type and Grm $1^{\text {crv } 4 / c r v 4}$ mice by using RT-PCR with primers specific for the cDNA region encompassing the crv4 mutation. In the wild-type sample, we obtained a band of $850 \mathrm{bp}$, which was sequenced to ascertain the Grm1 specificity of the RT-PCR product obtained. The result confirmed the expression of Grm1 in normal mouse renal tissue. In Grm1 $1^{\text {rrv } 4 / c r v 4}$ mouse renal tissue, by using the same RT-PCR approach as in the wild type, a unique band of $989 \mathrm{bp}$ was obtained (Figure 1B). After sequencing, this band appeared to consist of Grm1-specific cDNA enclosing the crv4 insertion mutation. No evidence of wild-type mRNA presence was obtained by means of
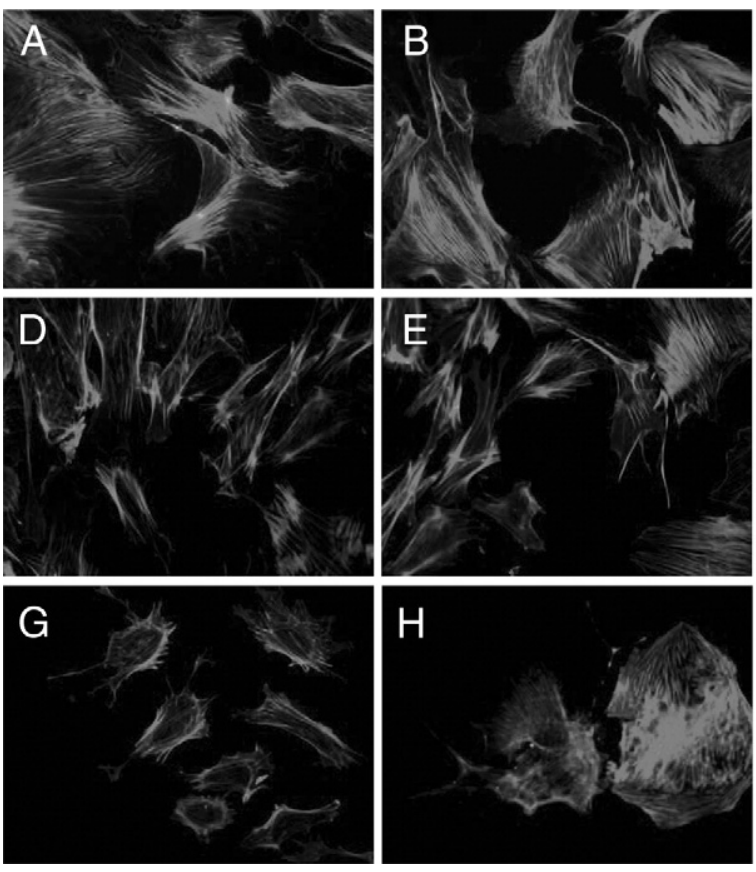
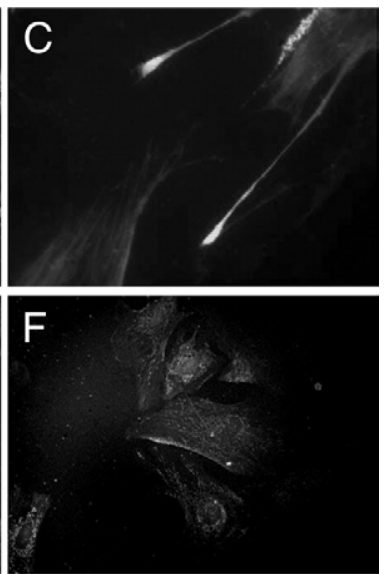

Figure 6. Immunofluorescence of primary podocytes. Compared with podocytes from wild-type mice (A-C), heterozygous-derived (D-F) and homozygous-derived (G-I) cells show remodeling of F-actin, with loss of stress fibers $(\mathbf{D}, \mathbf{E}, \mathbf{G}$, and $\mathbf{H})$ and progressive decrease of nephrin expression (F and $\mathbf{I})$. Original magnification: $\times 200(\mathbf{A}, \mathbf{B}, \mathbf{D}-\mathbf{G}) ; \times 400(\mathbf{C}, \mathbf{H}, \mathbf{I})$.

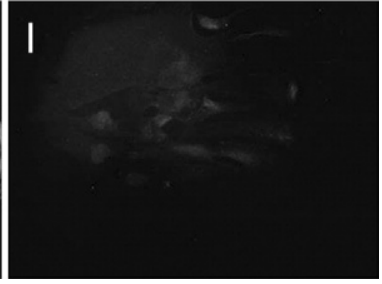


RT-PCR in different PCR conditions, even by using a high number of amplification cycles. Therefore, we assumed that, analogously to what we observe in the cerebellum, the only transcribed mRNA is the mutated one, and, as a consequence, a wild-type protein is not translated from the mutant transcript.

To further investigate the specific expression of Grm1 at the cellular level, we isolated renal glomeruli and obtained primary podocyte cell cultures from wildtype mice to be used in RT-PCR experiments. Immortalized mouse podocyte cells were used as well. A specific band for Grm1 was obtained from this material (Figure 1D).

To assess the quality of extracted RNA from either renal cortex or isolated glomeruli and podocytes, we performed RT-PCR experiments to amplify nephrin and podocin (Figure 1C) and nephrin and glyceraldehyde-3phosphate dehydrogenase (Gapdh) (Figure 1D). We then investigated the renal protein expression of Grm1 by using Western blotting and immunofluorescence on renal tissues obtained from wild-type and Grm1 crv4/crv4 mice. As shown in Figure 2A, a weak mGlu1-specific band (140 $\mathrm{kDa})$ is visible in the normal renal cortex and is absent from the Grm1 ${ }^{\text {crv4/crv4 }}$ mouse tissues. Because no mGlu1 receptor-specific band was visible even when using a large amount of lysates (up to $60 \mu \mathrm{g}$ of total proteins), we assumed that the receptor is absent from the renal cortex of Grm1 $1^{\text {crv4/crv4 }}$ animals.

Indeed, Grm1 protein was also detectable in protein extracts obtained from isolated glomeruli (Figure 2B). A mild shift in gel migration of the receptor mGlu1 band was detected between renal and cerebellum tissues. It is wellknown that mGlu1 receptors are subjected in different tissues to posttranslational modifications, such as glycosylation. ${ }^{26}$ Glycosidase treatment of the protein lysates reduced the apparent molecular weight observable by Western blot (see Supplemental Figure S2 at http://ajp. amjpathol.org). Although the presence of other posttranslational modifications and/or differences in the primary amino acid sequence might not be excluded, these data demonstrate that glycosylation may play a role in the molecular weight shift evidenced by immunoblotting.

Finally, we evaluated whether the presence of the half-dosage Grm1 gene in Grm1 ${ }^{+/ c r v 4}$ heterozygous mice could be associated with a corresponding decrease in mGlu1 receptor protein. Densitometric analyses of Grm1 bands normalized per Gapdh band indicated a mean \pm SE expression level of the Grm1 heterozygous band close to half that of the wild-type band $(60 \% \pm 8.7 \%$, heterozygous versus wild type; Figure 2, C and D).

As shown in Figure 3, these results were confirmed by means of immunofluorescence studies on mouse kidney tissues (Figure 3, A and B). Double stainings of Grm1 and nephrin disclosed glomerular co-staining (Figure 3, C-E), Immunogold electron microscopy confirmed the podocyte location of the receptor and its absence from glomeruli of homozygous Grm $1^{\text {crv } 4 / c r v 4}$ animals (Figure 3, F-H). Double staining on the podocyte cell line showed prevailing co-localization of Grm1 and nephrin along cell processes (Figure 3, I-N).

\section{Renal Phenotype of Grm1 ${ }^{\text {crv4/crv4 }}$ Mice}

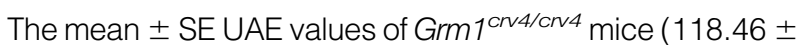
$23.30 \mu \mathrm{g} / \mathrm{mg}$ ) were more than threefold higher than those of control animals $(31.53 \pm 3.89 \mu \mathrm{g} / \mathrm{mg})(P=0.0001)$. Also, heterozygous Grm $1^{+/ \text {crv } 4}$ animals displayed higher mean \pm SE UAE values (93.41 $\pm 7.64 \mu \mathrm{g} / \mathrm{mg})$ than did control mice $(P=0.015)$ (Table 1 and see Supplemental Figure S3A at http://ajp.amjpathol.org).

Dividing the samples according to the animal age, it was possible to observe the progressive increase of albuminuria in Grm1 $1^{\text {crv4/crv4 }}$ animals, from low levels (UAE range, 8.95 to $221.51 \mu \mathrm{g} / \mathrm{mg}$ ) detected at 2 to 6 months to higher values in mice older than 6 months (UAE range, 55.27 to $423.65 \mu \mathrm{g} / \mathrm{mg}$ ). Instead, values remained constant in wild-type mice (UAE range at 2 to 6 months, 5.62
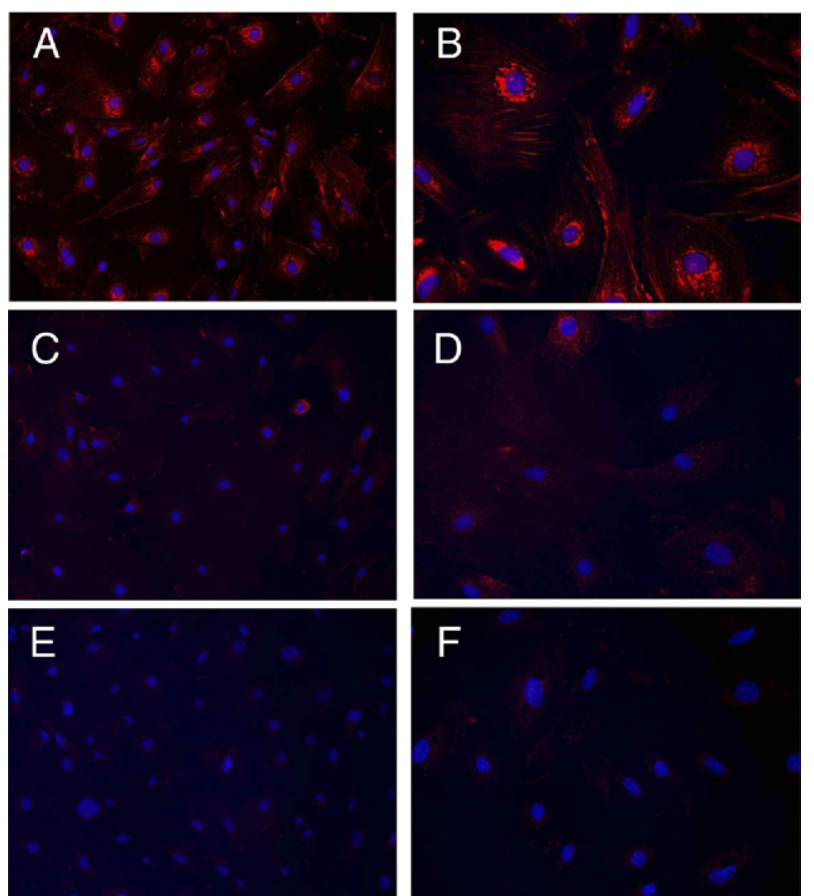

G

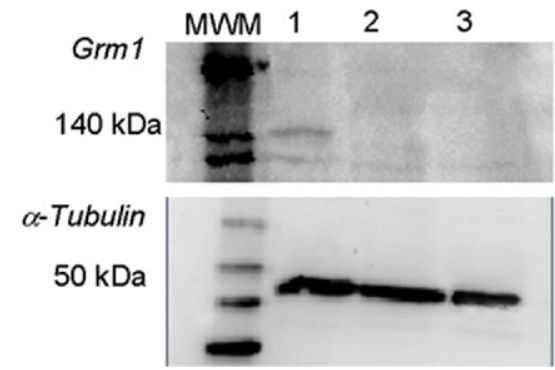

Figure 7. Grm1 silencing experiments. A: Grm1 staining in the podocyte cell line after transfection with scramble siRNA shows intact expression of Grm1. B: At higher magnification, Grm1 positivity along cell processes is more evident. Silencing with $10 \mathrm{nmol} / \mathrm{L}$ siRNA results in reduction of staining from most cells $(\mathbf{C})$, although some positivity can be observed at higher magnification (D). Complete silencing is reached by $20 \mathrm{nmol} / \mathrm{L}$ siRNA (E and F). DAPI nuclear counterstaining in all preparations demonstrates that there is no apoptotic or necrotic damage to the cells due to the transfection procedure. Original magnification: $\times 200(\mathbf{A}, \mathbf{C}, \mathbf{E}) ; \times 400(\mathbf{B}, \mathbf{D}, \mathbf{F})$. G: Western blot analysis of protein extracts from scramble siRNA (lane 1) shows a Grm 1 band, which is absent from cells silenced with $10 \mathrm{nmol} / \mathrm{L}-$ specific (lane 2) and $20 \mathrm{nmol} / \mathrm{L}$-specific (lane 3) siRNAs. $\alpha$-Tubulin is used as protein load control. MWM, molecular weight marker. 
to $57.21 \mu \mathrm{g} / \mathrm{mg}$; UAE range in mice older than 6 months, 8.80 to $60.12 \mu \mathrm{g} / \mathrm{mg}$ ).

The qualitative SDS-polyacrylamide gel electrophoresis analysis of urine samples (data not shown) and quantitative analyses revealed that the major protein found in the urine of mutant mice was serum albumin, indicating that proteinuria was likely due to defects of the glomerular filtration barrier.

\section{Grm $1^{\text {crv4/crv4 }}$ Mice Have an Alteration of Glomerular $P_{\text {alb }}$}

We investigated the glomerular $P_{\text {alb }}$ in isolated glomeruli of 7-month-old Grm1 $1^{\text {crv4/crv4 }}(n=4), G r m^{+/ c r v 4}(n=4)$, and $\mathrm{Grm}^{+/+}(n=5)$ mice. A significant increase in the $P_{\text {alb }}$ value (mean $\pm S D, 0.83 \pm 0.20$ ) was demonstrated in homozygous mutated mice compared with the wildtype strain (mean \pm SD, $0.16 \pm 0.20$ ) (see Supplemental Figure S3B at http://ajp.amjpathol.org). In the heterozygous group, two animals were characterized by altered mean $\pm S D P_{\text {alb }}$ values $(0.95 \pm 0.16)$ and two by normal mean $\pm S D P_{\text {alb }}$ values $(0 \pm 0.01)$

\section{Absence of Grm1 Leads to Defects in Glomerular Organization}

In kidneys from 2-month-old animals, light microscopy examination did not reveal major glomerular differences among mouse strains (see Supplemental Figure S4, A and B, at http://ajp.amjpathol.org). In older animals (4 to 8 months of age), glomeruli appeared normal by means of light microscopy (see Supplemental Figure S4C at http://ajp.amjpathol.org), whereas tubuli of homozygous Grm1 $1^{\text {rv } 4 / c r v 4}$ mice were filled with dense material (see Supplemental Figure S4D at http://ajp.amjpathol.org) that was positively stained by an antibody against mouse albumin (see Supplemental Figure S4F at http://ajp. amjpathol.org).

Using electron microscopy, only wild-type animals displayed normal features (see Supplemental Figure 5, A and D, at $h$ ttp://ajp.amjpathol.org; Figure 4A). Segmental foot process effacement was already detected in glomeruli from 2-month-old heterozygous $\mathrm{Grm} 1^{+/ \mathrm{crv} 4}$ mice (see Supplemental Figure S5, B and E, at http://ajp. amjpathol.org; Figure 4B), and homozygous Grm1 $1^{\text {rrv//crv4 }}$ animals at the same age showed diffuse foot process effacement and a convoluted and thickened glomerular basement membrane (see Supplemental Figure S5, C and F, at http://ajp.amjpathol.org; Figure 4C). Calculation of mean FPW demonstrated a progressive increase in heterozygous and homozygous mice (Figure 4D). Protein and lipid accumulation was evident in the proximal tubular cells of Grm1 ${ }^{\text {crv } 4 / c r v 4}$ mice (see Supplemental Figure S5 at http://ajp.amjpathol.org).

Electron microscopy of 8-month-old animals showed the persistence of normal glomerular features of wild-type mice (Figure 4, E and $\mathrm{H}$ ) and the worsening of glomerular damage in heterozygous (Figure 4, F and I) and homozygous (Figure 4, G and J) animals in terms of podocyte foot process effacement and basement membrane changes.

Immunofluorescence for podocyte proteins conducted on kidneys of 2-month-old Grm1 $1^{\text {crva/crv } 4}$ mice displayed diffuse reduction of nephrin (Grm1 ${ }^{+/+}$versus $\mathrm{Grm} 1^{\mathrm{crv} 4 / \mathrm{crv} 4}$, $P<0.001)$, segmental decrease of synaptopodin $\left(\mathrm{Grm} 1^{+/+}\right.$versus Grm1 $\left.{ }^{\mathrm{cr} 4 / \mathrm{crv} 4}, P<0.05\right)$ and ZO-1 (percentage of glomerular area, $\mathrm{Grm} 1^{+/+}$versus $\mathrm{Grm} 1^{\text {cru//crv4 }}$, $P<0.001$; and percentage of glomeruli, $P<0.05$ ) involving more than $40 \%$ of glomeruli. Only minor differences in podocin positivity were observed. No major alteration of podocyte proteins were clearly detectable at this time point in heterozygous animals, although a re-
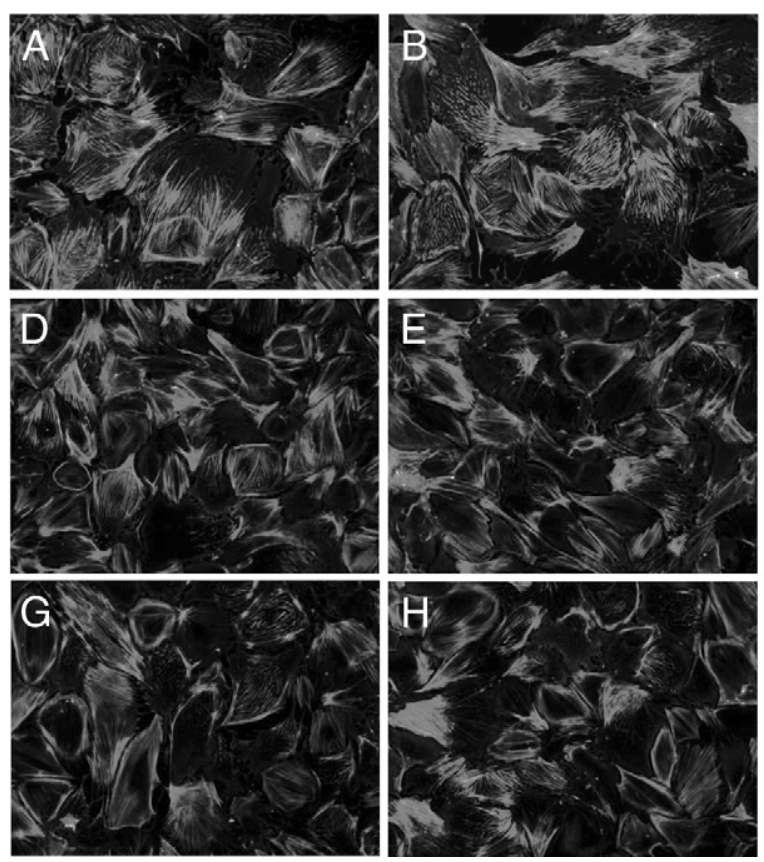
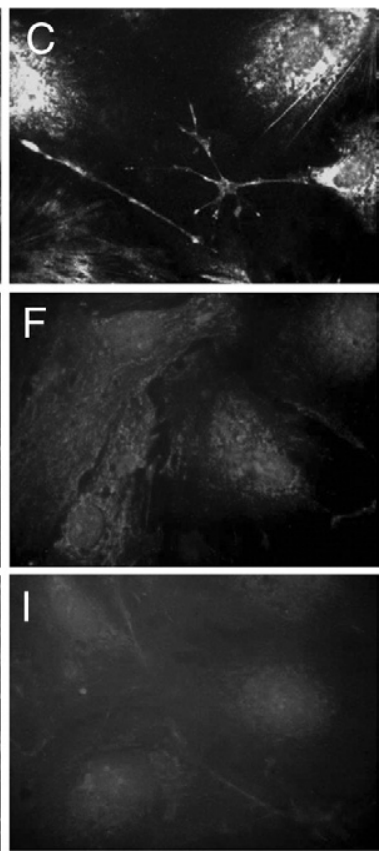

Figure 8. Cells transfected by scramble siRNA conserve actin stress fibers ( $\mathbf{A}$ and $\mathbf{B})$ and nephrin staining along cell processes $(\mathbf{C})$. Cell transfection by $10 \mathrm{nmol} / \mathrm{L}-$ specific (D-F) and 20 nmol/L-specific (G-I) siRNAs show remodeling of the actin cytoskeleton, with loss of stress fibers and peripheral actin staining in several cells (D, E, G, and $\mathbf{H})$ and loss of nephrin staining (F and I). Immunofluorescence; original magnification: $\times 200(\mathbf{A}, \mathbf{B}, \mathbf{D}, \mathbf{E}, \mathbf{G}$, and $\mathbf{H}) ; \times 630(\mathbf{C}, \mathbf{F}$, and $\mathbf{I}$. 
duction trend appeared from the quantitative evaluation (see Supplemental Figure S6 at http://ajp.amjpathol.org).

Older mice displayed a further reduction of nephrin, a segmental decrease of podocin and ZO-1, and a global reduction of synaptopodin not only in homozygous but also in heterozygous mice (Figure 5, A-L). Western blot comparative analyses of renal glomeruli from 8-monthold mice confirmed the reduction of most podocyte proteins in homozygous and heterozygous animals (Figure $5, \mathrm{M}$ and $\mathrm{N}$ ).

\section{Cultured Podocytes}

Immunofluorescence studies conducted on primary podocyte cell cultures obtained from mice of the three different genotypes showed a progressive reduction in nephrin staining in heterozygous and homozygous podocytes. Absence of one or two alleles of Grm1 was accompanied by remodeling of actin filaments, with loss of stress fibers and increased peripheral actin distribution. Cells from homozygous mice also showed randomly distributed, disorganized cytoplasmic actin (Figure 6). Silencing of Grm1 in the podocyte cell line (Figure 7) also caused actin remodeling with loss of stress fibers and peripheral actin distribution (Figure 8, D, E, G, and H) and reduction of nephrin staining, especially along cell processes (Figure 8, F and I).

\section{Adriamycin Nephropathy}

Injection of a low dosage of adriamycin did not cause major changes in wild-type animals, whereas it was sufficient to determine the appearance of protein casts and glomerular damage in kidneys of Grm1 $1^{\text {rvalorv4 }}$ mice (Figure 9, E-H).

\section{Discussion}

In neurons, through a mechanism involving the release of calcium from intracellular stores, the mGlu1 receptor triggers various signaling pathways that finally modulate neuron excitability, synaptic plasticity, and mechanisms of feedback regulation of neurotransmitter release. Distribution of mGlu1 receptors has been extensively studied in the central nervous system, with the highest expression in Purkinje cells of the cerebellar cortex, and has been recently detected also in non-nervous systems (reviewed by Nicoletti and colleagues ${ }^{20}$ and by Ferraguti et $\mathrm{al}^{8}$ ).

The present studies, by using different approaches, show that mGlu1 receptor is present in the kidney, particularly in glomerular podocytes. These data are in keeping with recently published human glomerular expression profiles obtained by means of cDNA microarray of transplant living donors, indicating that normal human glomeruli do express the mGlu1 receptor together with a complete series of neuron-specific molecules. ${ }^{1}$

These observations led us to hypothesize that mGlu1 receptor could be relevant to podocyte signaling and glomerular intercellular communication. To verify this hypothesis, we analyzed the possible appearance of a glo-
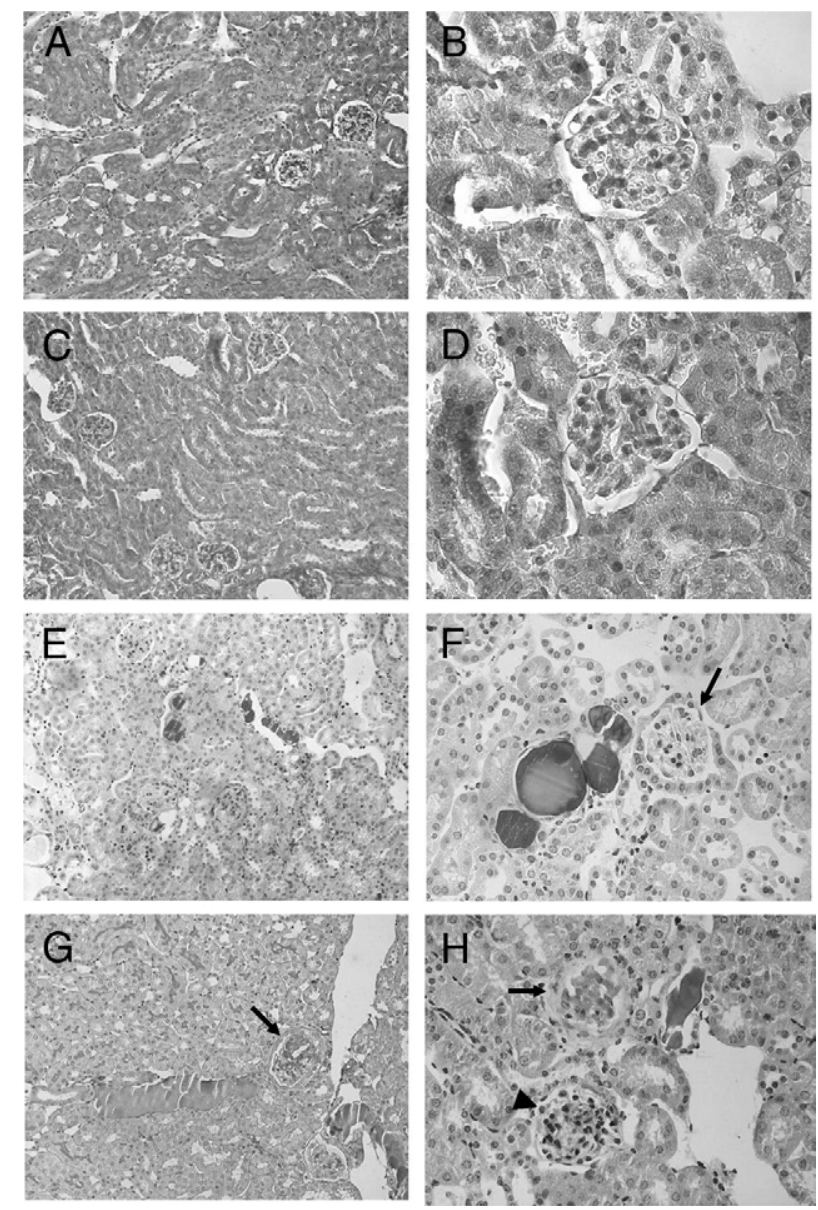

Figure 9. Effects of adriamycin injection on renal morphology. A: The renal tissue of saline-injected mice displays normal glomerular and interstitial features. B: A normal glomerulus. C: A renal section taken from a wild-type animal injected with a dose of $8 \mathrm{mg} / \mathrm{kg}$ body weight of adriamycin does not show signs of tubulointerstitial or glomerular damage. D: At higher magnification, a glomerulus looks completely normal. E: Tubular casts are present in a renal section of a Grm $1^{\text {crva/crva }}$ mouse injected with the same dosage of adriamycin. Different fields taken from the renal tissue of an adriamycininjected animal display tubular casts near normal (F) or damaged (G and $\mathbf{H})$ glomeruli, indicated by arrows. The represented damaged glomeruli show signs of segmental (G) or global (H, upper glomerulus, arrow) sclerosis. In $\mathbf{H}$, the lower glomerulus (arrowhead) displays increased cellularity, likely due to inflammatory cells. Acid Fuchsin Orange-G and PAS staining; original magnification: $\times 200(\mathbf{A}, \mathbf{C}, \mathbf{E}, \mathbf{G}) ; \times 400(\mathbf{F}, \mathbf{H}) ; \times 630(\mathbf{B}, \mathbf{D})$

merular phenotype in a mouse mutant lacking the mGlu1 receptor due to a spontaneous genetic mutation $\left(\mathrm{Grm} 1^{\mathrm{crv} 4}\right)$. As for the neurologic phenotype, we recently described that homozygous Grm1 crv//crv4 mice exhibit gait ataxia and intentional tremor because of cerebellar impairment due to the absence of mGlu1 receptor activity. On the contrary, heterozygous $\mathrm{Grm} 1^{+/ \mathrm{crv} 4}$ animals do not show evident cerebellar symptoms. ${ }^{21}$

The present analysis indicates not only that homozygous Grm $1^{\text {crv } 4 / c r v 4}$ mice display mild to moderate albuminuria that increases with time but also that heterozygous animals lose albumin into the urine. This phenomenon can possibly be explained either by better efficiency of the central nervous system in compensating one allele absence or by the presence of not-yet-identified minor central nervous system defects that will require more detailed investigation. 
As for the renal glomerulus, although light microscopy did not reveal major changes at any age, electron microscopy allowed us to detect several abnormalities, mostly involving podocyte foot processes, in homozygous and heterozygous Grm $1^{\text {crv } 4}$ animals, giving a histologic basis to the albumin leakage. Histologic defects are present since the animals are 2 months old, and they worsen with age. However, as frequently also occurs in human glomerulopathies, ${ }^{27}$ the severity of foot process effacement did not parallel the entity of proteinuria. In the present animals, this discrepancy seems, at least partly, to be due to the active tubular reabsorption, as indicated by albumin immunofluorescence and by the electron microscopy finding of droplets accumulation in proximal tubular cells. On the other hand, the lack of mGlu1 receptors in podocytes seems to be sufficient to increase podocyte susceptibility to toxic/environmental factors, as demonstrated by the experiments of low-dosage adriamycin treatment of Grm1 $1^{\text {crv } 4 / c r v 4}$ mice.

At the cellular level, major effects of the absence of one or two Grm1 alleles are represented by podocyte cytoskeletal changes, as evidenced by the variation of actin distribution into primary podocytes that accompanies the decreased nephrin expression, suggesting possible functional interactions among mGlu1 receptor and nephrin that will be the object of our subsequent studies. This was further confirmed by transient silencing of the Grm1 in a mouse podocyte cell line that is sufficient to cause similar changes in actin and nephrin.

In renal glomeruli, podocytes with their foot processes are responsible for counterforces that balance the distending forces exerted to the glomerular filter by the high transmural pressure gradient in glomerular capillaries. Thus, podocytes have to respond to mechanical stress, and they do it by reorganizing their cytoskeleton to provide a more motile phenotype. ${ }^{28}$ Inappropriate responses of the cytoskeleton to physiologic challenges may result in local podocyte damage, which across time may lead to loss of podocyte function and renal disease onset. ${ }^{29}$

As largely reported, in neuronal cells the C-terminal domain of mGlu1 receptors physically interacts with a variety of cytoskeletal, scaffolding, and signaling proteins (reviewed by Ferraguti and colleagues $^{8}$ ). In particular, the mGlu1 receptor presents a consensus sequence that binds to scaffolding proteins, namely, a (PSD-95)/diskslarge/ZO-1 (PDZ) domain binding sequence (residues SSSL). ${ }^{30}$ Different studies using in vitro and in vivo models support an important regulatory role for mGlu1 receptors in neuronal dendritic and spine morphology through mechanisms such as direct interactions with cytoskeletal proteins. ${ }^{13,31,32}$

Indeed, the Purkinje cells of mGlu1 receptor knockout mice, the cells in the nervous system in which the mGlu1 receptor is mainly expressed, exhibit a decrease in the overall extent of the branching complexity of their dendrites. ${ }^{33}$ In this respect, the present data showing reduction of nephrin, synaptopodin, and ZO-1 in glomeruli, together with cytoskeletal changes in podocytes from heterozygous and homozygous mice, seem to indicate that reduction and absence of the mGlu1 receptor induce a deep modification of the podocyte structure.
In conclusion, we are tempted to speculate that in podocytes, the mGlu1 receptor may act as a modulator of cell morphology through direct interactions with cytoskeletal proteins and that a loss of mGlu1 receptors could implicate an anomalous plasticity of podocyte foot processes leading to dysregulation of the filtration barrier, a common theme in many renal diseases.

\section{Acknowledgments}

We thank Dr. Jean-Louis Guénet for providing the animal model and encouraging its characterization and Prof. Rosanna Gusmano and the Renal Child Foundation for providing scientific advice.

\section{References}

1. Rastaldi MP, Armelloni S, Berra S, Calvaresi N, Corbelli A, Giardino LA, Li M, Wang GQ, Fornasieri A, Villa A, Heikkila E, Soliymani R, Boucherot A, Cohen CD, Kretzler M, Nitsche A, Ripamonti M, Malgaroli A, Pesaresi M, Forloni GL, Schlondorff D, Holthofer H, D'Amico G: Glomerular podocytes contain neuron-like functional synaptic vesicles. FASEB J 2006, 20:976-978

2. Giardino L, Armelloni S, Corbelli A, Mattinzoli D, Zennaro C, Guerrot D, Tourrel F, Ikehata M, Li M, Berra S, Carraro M, Messa P, Rastaldi MP: Podocyte glutamatergic signaling contributes to the function of the glomerular filtration barrier. J Am Soc Nephrol 2009, 20:19291940

3. Olive MF: Metabotropic glutamate receptor ligands as potential therapeutics for addiction. Curr Drug Abuse Rev 2009, 2:83-98

4. Nakanishi S: Molecular diversity of glutamate receptors and implications for brain function. Science 1992, 258:597-603

5. Fagni L, Chavis $\mathrm{P}$, Ango F, Bockaert J: Complex interactions between mGluRs, intracellular $\mathrm{Ca} 2+$ stores and ion channels in neurons. Trends Neurosci 2000, 23:80-88

6. Nicoletti F, Meek JL, ladarola MJ, Chuang DM, Roth BL, Costa E: Coupling of inositol phospholipid metabolism with excitatory amino acid recognition sites in rat hippocampus. J Neurochem 1986, 46: $40-46$

7. Rong R, Ahn JY, Huang H, Nagata E, Kalman D, Kapp JA, Tu J, Worley PF, Snyder SH, Ye K: PI3 kinase enhancer-Homer complex couples mGluRI to PI3 kinase, preventing neuronal apoptosis. Nat Neurosci 2003, 6:1153-1161

8. Ferraguti F, Crepaldi L, Nicoletti F: Metabotropic glutamate 1 receptor: current concepts and perspectives. Pharmacol Rev 2008, 60:536-581

9. Gao W, Dunbar RL, Chen G, Reinert KC, Oberdick J, Ebner TJ: Optical imaging of long-term depression in the mouse cerebellar cortex in vivo. J Neurosci 2003, 23:1859-1866

10. Hansel C, Linden DJ, D'Angelo E: Beyond parallel fiber LTD: the diversity of synaptic and non-synaptic plasticity in the cerebellum. Nat Neurosci 2001, 4:467-475

11. Kano M, Hashimoto K, Tabata T: Type-1 metabotropic glutamate receptor in cerebellar Purkinje cells: a key molecule responsible for long-term depression, endocannabinoid signalling and synapse elimination. Philos Trans R Soc Lond B Biol Sci 2008, 363:2173-2186

12. Musante V, Neri E, Feligioni M, Puliti A, Pedrazzi M, Conti V, Usai C, Diaspro A, Ravazzolo R, Henley JM, Battaglia G, Pittaluga A: Presynaptic mGlu1 and mGlu5 autoreceptors facilitate glutamate exocytosis from mouse cortical nerve endings. Neuropharmacology 2008, 55: 474-482

13. Catania MV, Bellomo M, Di Giorgi-Gerevini V, Seminara G, Giuffrida R, Romeo R, De Blasi A, Nicoletti F: Endogenous activation of group-I metabotropic glutamate receptors is required for differentiation and survival of cerebellar Purkinje cells. J Neurosci 2001, 21:7664-7673

14. Garcia-Junco-Clemente P, Linares-Clemente P, Fernandez-Chacon R: Active zones for presynaptic plasticity in the brain. Mol Psychiatry 2005, 10:185-200 
15. Luccini E, Musante V, Neri E, Brambilla Bas M, Severi P, Raiteri M, Pittaluga A: Functional interactions between presynaptic NMDA receptors and metabotropic glutamate receptors co-expressed on rat and human noradrenergic terminals. Br J Pharmacol 2007, 151:10871094

16. Gu Y, Publicover SJ: Expression of functional metabotropic glutamate receptors in primary cultured rat osteoblasts: cross-talk with $\mathrm{N}$-methyl-D-aspartate receptors. J Biol Chem 2000, 275:34252-34259

17. Storto M, Sallese M, Salvatore L, Poulet R, Condorelli DF, Dell'Alban P, Marcello MF, Romeo R, Piomboni P, Barone N, Nicoletti F, De Blasi A: Expression of metabotropic glutamate receptors in the rat and human testis. J Endocrinol 2001, 170:71-78

18. Miglio G, Varsaldi F, Dianzani C, Fantozzi R, Lombardi G: Stimulation of group I metabotropic glutamate receptors evokes calcium signals and $\mathrm{c}$-jun and $\mathrm{c}$-fos gene expression in human $\mathrm{T}$ cells. Biochem Pharmacol 2005, 70:189-199

19. Pacheco R, Ciruela F, Casado V, Mallol J, Gallart T, Lluis C, Franco R: Group I metabotropic glutamate receptors mediate a dual role of glutamate in T cell activation. J Biol Chem 2004, 279:33352-33358

20. Nicoletti F, Battaglia G, Storto M, Ngomba RT, lacovelli L, Arcella A, Gradini R, Sale P, Rampello L, De Vita T, Di Marco R, Melchiorri D, Bruno V: Metabotropic glutamate receptors: beyond the regulation of synaptic transmission. Psychoneuroendocrinology 2007, 32(Suppl 1):S40-S45

21. Conti V, Aghaie A, Cilli M, Martin N, Caridi G, Musante L, Candiano G, Castagna M, Fairen A, Ravazzolo R, Guenet JL, Puliti A: crv4, a mouse model for human ataxia associated with kyphoscoliosis caused by an mRNA splicing mutation of the metabotropic glutamate receptor 1 (Grm1). Int J Mol Med 2006, 18:593-600

22. Rastaldi MP, Armelloni S, Berra S, Li M, Pesaresi M, Poczewski H, Langer B, Kerjaschki D, Henger A, Blattner SM, Kretzler M, Wanke R, D'Amico G: Glomerular podocytes possess the synaptic vesicle molecule Rab3A and its specific effector rabphilin-3a. Am J Pathol 2003, 163:889-899

23. Carraro M, Caridi G, Bruschi M, Artero M, Bertelli R, Zennaro C, Musante L, Candiano G, Perfumo F, Ghiggeri GM: Serum glomerular permeability activity in patients with podocin mutations (NPHS2) and steroid-resistant nephrotic syndrome. J Am Soc Nephrol 2002 , 13:1946-1952

24. Deegens JK, Dijkman HB, Borm GF, Steenbergen EJ, van den Berg JG, Weening JJ, Wetzels JF: Podocyte foot process effacement as a diagnostic tool in focal segmental glomerulosclerosis. Kidney Int 2008, 74:1568-1576

25. Pippin JW, Brinkkoetter PT, Cormack-Aboud FC, Durvasula RV, Hauser PV, Kowalewska J, Krofft RD, Logar CM, Marshall CB, Ohse $\mathrm{T}$, Shankland SJ: Inducible rodent models of acquired podocyte diseases. Am J Physiol Renal Physiol 2009, 296:F213-F229

26. Mody N, Hermans E, Nahorski SR, Challiss RA: Inhibition of N-linked glycosylation of the human type $1 \alpha$ metabotropic glutamate receptor by tunicamycin: effects on cell-surface receptor expression and function. Neuropharmacology 1999, 38:1485-1492

27. van den Berg JG, van den Bergh Weerman MA, Assmann KJ, Weening JJ, Florquin S: Podocyte foot process effacement is not correlated with the level of proteinuria in human glomerulopathies. Kidney Int 2004, 66:1901-1906

28. Faul C, Asanuma K, Yanagida-Asanuma E, Kim K, Mundel P: Actin up: regulation of podocyte structure and function by components of the actin cytoskeleton. Trends Cell Biol 2007, 17:428-437

29. Pavenstadt $H$, Kriz W, Kretzler M: Cell biology of the glomerular podocyte. Physiol Rev 2003, 83:253-307

30. Tu JC, Xiao B, Naisbitt S, Yuan JP, Petralia RS, Brakeman P, Doan A, Aakalu VK, Lanahan AA, Sheng M, Worley PF: Coupling of mGluR/ Homer and PSD-95 complexes by the Shank family of postsynaptic density proteins. Neuron 1999, 23:583-592

31. Sirzen-Zelenskaya A, Zeyse J, Kapfhammer JP: Activation of class I metabotropic glutamate receptors limits dendritic growth of Purkinje cells in organotypic slice cultures. Eur J Neurosci 2006, 24:29782986

32. Vanderklish PW, Edelman GM: Dendritic spines elongate after stimulation of group 1 metabotropic glutamate receptors in cultured hippocampal neurons. Proc Natl Acad Sci USA 2002, 99:1639-1644

33. Aiba A, Kano M, Chen C, Stanton ME, Fox GD, Herrup K, Zwingman TA, Tonegawa S: Deficient cerebellar long-term depression and impaired motor learning in mGluR1 mutant mice. Cell 1994, 79:377-388 